\title{
STRATEGIES FOR ATTAINING SUSTAINABLE DEVELOPMENT GOALS FOR PERSONS WITH DISABILITIES IN SOUTH-SOUTH GEOPOLITICAL ZONE OF NIGERIA
}

\author{
Samuel Orim \\ Institute of Special Educatıon, Faculty of Education, Palacky Unıversıty Olomouc, Czech Republic \\ Samuelorim1@gmail.com
}

\begin{abstract}
This study investigated strategies for achieving sustainable inclusive education in South-south Geopolitical Zone of Nigeria. A survey of two hundred (200) participants comprising of key actors of Sustainable Development Goals such as Desk Officers Ministry of Education, members of National Assembly and House Representatives, etc. from South-south Geopolitical Zone of Nigeria selected through expert sampling technique. Three null hypotheses were formulated to direct the study. A twenty (20) item questionnaire with a four point rating scale and reliability coefficient of 0.76 was used to canvass opinions of these stakeholders on the effectiveness of strategies such as establishment of National Commission on Sustainable Development for Persons with Disabilities, workable follow up mechanisms and disaggregated data by disability so to establish a link between these strategies and achievement of sustainable inclusive education. The data collected were statistically analyzed using Pearson Product Moment Correlation Analysis. The findings revealed that these strategies are effective and significantly related with achievement of sustainable inclusive education. It was recommended that the government should establish workable follow up mechanisms at federal, state and local government levels to monitor, evaluate and hold key national SDGs actors accountable for implementation of the development agenda
\end{abstract}

Keywords: disability, development and sustainable

\section{INTRODUCTION}

Education is regarded as a platform that facilitates development process and a hub with which the universal vision depends for its realization in any nation. This is the reason why UNESCO in conjunction with the international community have over the decades committed efforts in setting the global goals to universalize education and ensure that its provision benefit all children and delivered in compliance with the global best practices. Thus, the provision of sustainable inclusive education is now a global concern. Nations all over the world are making effort to ensure equal educational opportunities to all children. According to Upah and Egbe (2012) to bring this to reality, various international agreements, conventions, and declarations have consistently formed the basis in educational provision globally. Examples of these include the Convention for Right of the Child (UNICEF, 1989), World Declaration for Education for All (UNESCO, 1990), the Standard Rules on the Equalization of Opportunities for Persons with Disabilities (United Nations, 1993), the UNESCO Salamanca Statement and Framework for Action (1994), and the Dakar Framework for Action (2000). The Dakar Framework was focused on "Education for All" by 2015. These international pronouncements and declarations greatly influenced governmental policies on the education of children with special needs, especially in developing countries. Most developed countries, especially the United States, had decades of experience to establish and reform their public education systems to guarantee appropriate education for children with special needs. The United States have make remarkable efforts to achieving this global vision by promulgating popular laws such as No Child Left Behind (NCLB, 2002) and the 
IJAEDU-International E-Journal of Advances in Education, Vol. 3, Issue 8, August 2017

Individuals with Disabilities Education Act 2004 while in the United Kingdom, Equality Act, 2010 has be enforced to cater for educational needs and meet the global vision. On the contrary, developing countries like Nigeria are just in the pioneering states of providing public education for children with special needs (Forlin \& Yaya, 2014).

This is evident in Nigeria by being signatory to the 1990 Millennium Development Goals (MDGs). The Millennium Development Goals (MDGs) marked a historic and effective method of global mobilization to achieve a set of important education priorities worldwide. Nigeria made substantial progress towards achievement of the Millennium Development Goal Two (which was education) particularly in special education by formulating educational policies that capture the educational needs of persons with disabilities in the country. This reflected the commitment of the Federal Government toward the provision of special education within the ambit of the Millennium Development Goals. Regrettably, in 2015, special education in Nigeria did not achieve a global standard as proposed by UNESCO (Abimbola \& Egeno 2013). The probable shortfall in achievement of the MDGs in area of special education is indeed serious, regrettable, and deeply painful as special education in Nigeria still face a myriad of challenges despite appreciable national efforts. The shortfall represents a set of operational failures that implicate many stakeholders and governments. Promises of Federal Government, the official development assistance by rich countries, as well as the collaborative partnership with international agencies, for example, was not kept.

For these reasons, one of the main outcomes from the UN Conference on Sustainable Development in 2012 was international agreement to negotiate a new set of global Sustainable Development Goals (SDGs) to guide the path of sustainable development in the world after the failure of developing countries like Nigeria to achieve MDGs in 2015 particularly in the provision of quality special needs education. Sustainable Development Goals (SDGs) are set to perpetuate and consolidate the efforts of the Federal Government of Nigeria and bringing a new age in achieving quality special needs education in Nigeria. Sustainable Development Goals are the same and offshoot of MDGs with expansive vision, reinvigorating and reauthorizing global commitments with success-oriented strategies to forestall the seeming failure of MDGs in most developing countries. Sustainable Development Goal Four captures education as stated by UN General Assembly (2015). The Goal Four which is the thrust of this work states thus: ensure inclusive and equitable quality education and promote lifelong learning opportunities for all. Unlike its precedent MDGs, the 2030 Agenda (for education) in its Sustainable Development Goals include two targets explicitly referencing to persons with disabilities and their needs (Dullar \& Ekeye, 2014). Proliferation of national and regional mechanisms is setting pace globally towards achieving this goal particularly for children with disabilities. This 2030 Agenda for Sustainable Development sets a new and encouraging phase in area of disability and development. The Agenda is built on the principle of leaving no one behind, implicitly promoting the inclusion of persons with disabilities.

Olise and Rawat (2013) noted that SDGs has again brought hope and recommitment in special needs provision in Nigeria as ample opportunity has been given to evaluate the vain strategies taken to achieve MDGs so as the setup success-oriented actions towards achieving SDGs. With SDGs, the questions that come to mind is why did Nigeria fail in achieving MDGs in the provision of special needs education and what is the prospect for SDGs? Research have demonstrated that many developed countries achieved MDGs for special needs children by taken pragmatic efforts to expanding and localizing the global indicators to capture the educational needs of children with special needs with adequate statistical and success-oriented follow-up mechanisms. Thus, Follow-up and review is a key aspect of the 2030 Agenda for Sustainable Development. The 2030 Agenda for Sustainable Development calls for a robust follow-up and review process to track progress toward the Sustainable Development Goals (SDGs). The 2030 Agenda promotes a robust, voluntary, effective, participatory, transparent and integrated followup and review framework that will make a vital contribution to implementation and will help countries to maximize and track progress to ensure that no one is left behind (Gounla \& Esheh, 2015).

Also, many developed and second world countries made significant progress in achieving MDGs by constituting a commission (with nominal variations) to occupy the central hub in the implementation of MDGs. Thus, Nigeria to avoid the national flop recorded in the MDGs is constitutionally required to setup such as body with a name "National Commission on Sustainable Development for Persons with Disabilities". The Commission's key task will be to boost the implementation of the 2030 Agenda for Sustainable Development, and to integrate it as a key element of national sustainable development work, while monitoring and assessing the realization of the global Agenda 2030 in Nigeria. The strength of this broad-based Commission will lie in its joint approach to monitoring progress and ensuring that society achieves its common goals collectively.

Finally, ensuring that the statistical systems are in place to track progress and ensure accountability, with the engagement of citizens, parliaments and other national stakeholders. This is especially critical to the most excluded and marginalized populations, which are often not represented or under-represented in current national data collection. In MDGs, national level indicators needed more attention, data were often not collected or disaggregated to reveal the insignificant population (those with disabilities) and, perhaps most significantly, data collection was not well-linked to decision making. The 2030 Agenda also requires follow up and review processes to be informed by country-led evaluation and notes the need to build capacity for national data systems and evaluation programmes as well as instituting a commission to facilitate the implementation process of SDGs. These become positive footing for the achievement of SDGs for special needs children in Nigeria. It is against this 
background that research is conceive to investigate new and effective strategies to achieving SDG Four for special needs children in Nigeria as the achievement of SDGs is strictly based on the amount of lesson drawn from MDGs flop.

\subsection{Statement of the problem}

There is no gainsaying the fact that with giant strides and commitment over the decade, Nigeria did not as expect meet the target of Millennium Development Goals for persons with disabilities in the area of education as targeted. The UN General Assembly adopted the new development agenda "Transforming our world: the 2030 agenda for sustainable development to reinvigorate nations of the world toward attaining universal development. Research and experience revealed workable follow up mechanisms were weak without disaggregated data for planning and implementation. Furthermore, the inadequacy of mechanisms designed to hold key educational stakeholders responsible through a constituted instrument like National Commission on Sustainable Development for Persons with Disabilities, has been frequently recognized as key factors undermining MDGs achievement. Drawing on from antecedent failure in MDGs achievement in Nigeria, it becomes worrisome as to what success-oriented strategies are to be adopted to benchmark other nations in the achievement of SDGs to avoid recurrent national flop. It is in solving this national and global challenge in Nigeria that this research is necessitated to find out the possible effectiveness of strategies such as instituting a body like National Commission on Sustainable Development for Persons with Disabilities, workable follow up mechanisms and disaggregated baseline data by disabilities in Nigeria. The problem of this study is conceptualized as how effective are these strategies in ensuring sustainable inclusive education for persons with disabilities in Nigeria?

\subsubsection{Purpose of the study}

The purpose of this study was to investigate strategies for attaining sustainable inclusive education for persons with disabilities in South-south Geopolitical Zone of Nigeria. Specifically, it aimed at finding the relationship between:

1. Establishment of National Commission on Sustainable Development for Persons with Disabilities and attainment of sustainable inclusive education

2. Establishment of workable follow up mechanisms and attainment of sustainable inclusive education

3. Disaggregation of baseline data by disability and attainment of sustainable inclusive education

\subsubsection{Research hypothesis}

To direct the study, three null hypotheses were formulated:

1. There is no significant relationship between establishment of National Commission on Sustainable Development for Persons with Disabilities and attainment of sustainable inclusive education

2. There is no significant relationship between establishment of workable follow up mechanisms and attainment of sustainable inclusive education.

3. There is no significant relationship between disaggregation of baseline data by disability and attainment of sustainable inclusive education

\section{METHODOLOGY}

The research adopted a survey and expert sampling technique was used to sample 200 (two hundred) key actors of Sustainable Development Goals such as Desk Officers Ministry of Education, members of National Assembly and House Representatives, members of disability professional associations, key political leaders and members of the Judiciary from South-south Geopolitical Zone of Nigeria selected through expert sampling technique. The instrument for data collection was a questionnaire of twenty (20) items with a 4 point rating scale. It was used to survey opinions on strategies for attaining sustainable inclusive education for persons with disabilities. The instrument was validated by three experts and has reliability coefficient of 0.76 obtained through Cronbach Alpha method of determining reliability. Pearson Product Moment Correlation Analysis was used to analyze the data obtained from field.

\section{PRESENTATION OF RESULT}

\subsection{Research hypothesis one}

There is no significant relationship between establishment of National Commission on Sustainable Development for Persons with Disabilities and attainment of sustainable inclusive education. The hypothesis testing and its analysis are done in Table 1 below. 
Table1: Pearson Product Moment Correlation Analysis of the Relationship between establishment of National Commission on Sustainable Development for Persons with Disabilities and attainment of sustainable inclusive education $(\mathrm{N}=200)$.

\begin{tabular}{|l|l|l|l|l|l|l|}
\hline Variables & Mean & $\begin{array}{l}\text { Standard } \\
\text { Deviation }\end{array}$ & $\begin{array}{l}\Sigma X^{2} \\
\Sigma Y^{2}\end{array}$ & $\Sigma X Y$ & Sig & $r$ \\
\hline $\begin{array}{l}\text { Establishment of National Commission on } \\
\text { Sustainable Development for Persons with } \\
\text { Disabilities }\end{array}$ & 9.55 & 4.23 & 800.21 & & & \\
\hline $\begin{array}{l}\text { Attainment of sustainable inclusive } \\
\text { education }\end{array}$ & 9.43 & 4.14 & 1184.07 & 675.05 & 0.002 & 0.51 \\
\hline
\end{tabular}

$\mathrm{P}<0.05$ Degree of Freedom $(\mathrm{df})=198$

The analysis in Table 1 showed that establishment of National Commission on Sustainable Development for Persons with Disabilities has a Mean of 9.55 and Standard Deviation of 4.23 and attainment of sustainable inclusive education has a Mean of 9.43 and Standard Deviation of 4.14. These correlated variables produced an $\mathrm{r}=$ 0.51 and it is significant at $p<0.05$ at degree of freedom of 198. This revealed that establishment of National Commission on Sustainable Development for Persons with Disabilities has a positive and significant correlation with sustainable inclusive education. Therefore, the null hypothesis was rejected. This indicates that establishment of National Commission on Sustainable Development for Persons with Disabilities is a sine qua non and effective institution which plans, monitors, evaluates and ensures that Government and other concerned agencies are accounted for sustainable inclusive education for persons with disabilities in Nigeria.

\subsection{Research hypothesis two}

There is no significant relationship between establishment of workable follow up mechanisms and attainment of sustainable inclusive education. The hypothesis testing and its analysis are done in Table 2 below.

Table 2: Pearson Product Moment Correlation Analysis of the Relationship between establishment of workable follow up mechanisms and attainment of sustainable inclusive education $(\mathrm{N}=200)$

\begin{tabular}{|l|l|l|l|l|l|l|}
\hline Variables & Mean & $\begin{array}{l}\text { Standard } \\
\text { Deviation }\end{array}$ & $\begin{array}{l}\Sigma X^{2} \\
\Sigma Y^{2}\end{array}$ & $\Sigma X Y$ & Sig & $r$ \\
\hline $\begin{array}{l}\text { Establishment of workable follow up } \\
\text { mechanisms }\end{array}$ & 10.44 & 4.41 & 989.76 & & & \\
\hline $\begin{array}{l}\text { Attainment of sustainable inclusive } \\
\text { education }\end{array}$ & 9.43 & 4.14 & 1184.07 & 751.50 & 0.001 & 0.76 \\
\hline
\end{tabular}

$\mathrm{P}<0.05$ Degree of Freedom (df) $=198$

The Table Two above revealed that the Mean of establishment of workable follow up mechanisms is 10.44 and standard deviation is 4.41 while attainment of sustainable inclusive education has a Mean of 9.43 and Standard Deviation of 4.14. The correlation coefficient $(r=0.76)$ obtained from the correlated variables is significant at $p<0.05$. The result shows that establishment of workable follow up mechanisms is positively and significantly related with sustainable inclusive education. By this result, the null hypothesis was rejected. This result shows that establishing workable follow up mechanisms to monitor and evaluate sustainable inclusive education activities key to achieving this goal.

\subsection{Research hypothesis three}

There is no significant relationship between disaggregation of baseline data by disability and attainment of sustainable inclusive education. The hypothesis testing and its analysis are done in Table 3 below.

Table 3: Pearson Product Moment Correlation Analysis of the Relationship between disaggregation of baseline data by disability and attainment of sustainable inclusive education $(\mathrm{N}=200)$

\begin{tabular}{|l|l|l|l|l|l|l|}
\hline Variables & Mean & $\begin{array}{l}\text { Standard } \\
\text { Deviation }\end{array}$ & $\begin{array}{l}\Sigma \mathrm{X}^{2} \\
\Sigma \mathrm{Y}^{2}\end{array}$ & $\Sigma \mathrm{XY}$ & Sig & $\mathrm{r}$ \\
\hline $\begin{array}{l}\text { Disaggregation of baseline data by } \\
\text { disability }\end{array}$ & 9.78 & 4.35 & 962.00 & & & \\
\hline $\begin{array}{l}\text { Attainment of sustainable inclusive } \\
\text { education }\end{array}$ & 9.43 & 4.14 & 1184.07 & 711.44 & 0.002 & 0.63 \\
\hline
\end{tabular}

$\mathrm{P}<0.05$ Degree of Freedom (df) $=198$ 
The above Table revealed that the Mean of disaggregation of baseline data by disability is 9.78 and standard deviation is 4.41 while attainment of sustainable inclusive education has a Mean of 9.43 and Standard Deviation of 4.14. The correlation coefficient $(r=0.63)$ obtained is significant at $p<0.05$. The result shows that establishment of follow up mechanisms has a positive and significant relationship with sustainable inclusive education. By this result, the null hypothesis was rejected. This result shows that establishing an enforceable follow up mechanisms to monitor and evaluate sustainable inclusive education activities key to achieving this goal.

\section{DISCUSSION}

It is deduced from the findings of Hypothesis 1that establishment of National Commission on Sustainable Development for Persons with Disabilities is quintessential in the pursuit of global vision in 2030 Development Agenda on sustainable inclusive education. The establishment of a National Commission on Sustainable Development for Persons with Disabilities will serve as a platform that localizes and sets up national targets to reflect the global goal for sustainable inclusive education. It role should be key and oversee the palming, monitoring and implementation as well as holding the Government accountable for SDGs national goals for persons with disabilities. According to Diabi and Luku (2012) the National Commission on Sustainable Development for persons with Disabilities should be an influential sustainable development forum bringing together key actors in Nigeria. It is based on a unique hybrid model, combining high-level political leadership with wide-ranging participation by civil society. Members of this Commission should include persons with disabilities, members of disabilities professional bodies, top government officials, members of the judiciary etc.

The aim of this Commission should be to embed sustainable development for persons with disabilities in all areas and in particular sustainable inclusive education in decision making and policy, involve society as a whole in the implementation of sustainable development, promote encounters, dialogue and networking between various actors, and share and communicate on best practices in sustainable development at both national and international level. The Commission's key task would be to boost the implementation of the 2030 Agenda for Sustainable Development, and to integrate it as a key element of national sustainable development work, while monitoring and assessing the realization of the global Agenda 2030 in Nigeria. The strength of this broad-based Commission lies in its joint approach to monitoring progress and ensuring that Nigeria achieves SDGs collectively for persons with disabilities. Another key task is to promote, monitor and assess the implementation of the Nigeria's commitment to Sustainable Development for persons with disabilities to ensure equality in compliance to No One Left Behind (Hugh \& Jage, 2013). The commission is to also communicate the results, multiply the number of operational commitments, raise the target level and enhance the effectiveness of the commitment process. A further key task for such a Commission involves ensuring that the objectives and principles of Nigeria's commitment to Sustainable Development for persons with disabilities are integrated into national policy. It should also ensure that national sustainable development policy for this neglected population is mainstreamed within central Government. Similarly, Akuaya (2007) supported that in order to strengthen commitment to the achievement of the sustainable inclusive education, there is need to establish such a body to advocate for quality inclusive education for persons with disabilities. National Commission on Sustainable Development for Persons with Disabilities (PWDs) will serves as a body charge with the responsibility of holding accountable all national stakeholders responsible for achievement of sustainable development goals for persons with disabilities. It quite unfortunate no such body is reason why even the existing policies have no positive effects on the lives of persons with disabilities.

The commission if constituted should develop programmes and projects within the National Development plans aimed at enhancing the status, development and acceptability of the persons with disabilities within the school community as well as establish throughout the Federal Republic of Nigeria as appropriate, vocational educational and rehabilitation centers specially designed, to meet the needs of the persons with disabilities. This body in other countries ensures that it monitors the response of various governmental agencies and other bodies concerned with the welfare of the disabled, and consistently enforces through the legal process whenever necessary in collaboration with the appropriate agencies the rights that accrue to those with disabilities under the laws. It should play a key role in the national implementation, assessment and monitoring of Agenda 2030. It could be also integral to the coordination mechanism and acts as a watchdog in the planning and implementation of sustainable inclusive education for persons with disabilities in Nigeria (Ughali \& Hualo, 2014).Oluwole and Akinbile (2015) in line with these findings observed that the unavailability of National Commission on Sustainable Development for Persons with Disabilities in Nigeria is inhibiting every pragmatic effort of the Government and other agencies towards achieving SDGs, and it is rendering sustainable inclusive education provision in Nigeria a jingle of no meaning as in the case of MDGs.

Similarly, the implication of the findings of Hypothesis 2 is that achievement of sustainable inclusive education cannot be successfully achieved without workable follow up mechanisms to monitor implementation and evaluate outcome of sustainable inclusive education. In agreement with these findings, Buskara and Tope (2009) maintained that follow up mechanisms a general process for controlling and monitoring the status of SDGs implementation for persons with disabilities to ensure that its goals are achieved. The key goal of the follow up process is to monitor and evaluate the course of the activities and adjust activities when needed to ensure 
effectiveness of outcome. Follow up mechanism starts with the beginning of SDGs activities, lasts throughout implementation, and ends up with completion the goals. In line with the findings of this study, Mener and Held (2007) corroborated that follow up mechanism encompasses activities such as setting of goals, developing strategies, outlining the implementation arrangements and allocating resources to achieve sustainable inclusive education for persons with disabilities. It is a way in which Nigeria brings to reality and sees to completion the universal goals for persons with disabilities particularly in the area of education. Furthermore, it is concerned with ongoing process by which key actors obtain regular feedback on the progress being made towards achieving sustainable inclusive education. It is concerned with the rigorous and independent assessment of either completed or ongoing sustainable inclusive education practices to determine the extent to which they are achieving stated objectives and contributing to decision making. In order to measure progress on the sustainable inclusive education for persons with disabilities, there must be robust follow up mechanisms established and implemented at local, national, regional and global levels by the Commission. Follow-up and review processes should include all stakeholders responsible for realizing sustainable development outcomes.

Some stakeholders have suggested that the follow-up and review processes under the post-2015 framework should extend beyond national governments to a wide range of stakeholders, including private sector enterprises, intergovernmental institutions and multilateral development agencies, and civil society (UNDG, 2015b). Each of these groups should be responsible for their commitments, and in reviewing commitments made by others. There has already been widespread discussion and support for including this wider range of actors within the follow-up and review framework. A shared vision of what follow-up means will be critical to the design of a review system that is robust and that promotes real progress towards sustainable inclusive education for persons with disabilities.

Deduction can also be made from the findings of Hypothesis 3 that disaggregation of baseline data by disabilities will help to reveal the population of persons with disabilities so as allocate adequate material and develop manpower resources that promote achievement of sustainable inclusive education. Eriet and Kufre (2012) in supporting the findings of this study lamented that there is a real paucity of robust statistical data with regard to disability issues in Nigeria. The world as it is known it today is driven by an increasing premium on reliable data which constitutes an integral part of policy formulation. Governments across the globe like never before, have come to appreciate the undeniable role that reliable data plays in national development. In Nigeria, the case is not different. At the National Bureau of Statistics, which is Nigeria's custodian of all official statistics on socio-economic and macro-economic indicators, various machinery and tools are to be brought to bear in improving the efficiency and reliability of official statistics disaggregated by disability. Shortcomings in the availability of consistent and reliable data have been an ongoing challenge in the area of disability and development. In 2000, when the Millennium Development Goals (MDGs) were established, disability data were scarce and often of poor quality in Nigeria. Comparable measures to identify persons with disabilities had not yet been developed in Nigeria. The MDGs did not include any target on disability and the monitoring of the MDGs did not focus on disability inclusion. None of the MDG indicators was ever disaggregated by disability at the global level (Wale \& Futar, 2015).

In agreement with these findings, Opara and Akanbi (2005) supported that the statistical knowledge of the population of Nigerians with disability is central and fundamental in the pursuit of the global vision as it provides information for effective national planning on sustainable inclusive education, and planning for the future. It also serves as a basis for resource distribution such as provision of scholarships, assistive technologies, disability empowerment programmes, mobility devices, and admission into schools. The educational and economic development of persons with disabilities in Nigeria would have been much easier if reliable population data were available because the absence of trustworthy or accurate population data directly affects the government's inability to ensure balanced economic empowerment and equal access to education, healthcare provision etc. But it is unfortunate that in these 21st century Nigeria still does not use effective and trustworthy census data to record the number of persons with disabilities for effective educational planning and the provision of other facilities. Thus, when a nation does not know the proportion and the total number of its citizens with disabilities, its planning process is likely to be haphazard, in the sense that less resources may be allocated to the areas or region which are in need of such resources. The elementary principle for planning and development of persons with disabilities in any nation is for the government to have access to a reliable and detailed demographic data of this population. The linkage between population census and the empowerment of this population is inseparable. Population census data are critically important in achieving equitable education and other SDGs targets for persons with disabilities. It can as well set priorities for future development and progress within the disability community (UN Development Group, 2015).

Every nation needs to have an accurate statistical knowledge of its population with disabilities for it to have an orderly plan for equity and the mainstreaming of this population into all the domains of the society. Population census data influences government policies on how much money should be spent on social amenities such as inclusive schools, inclusive healthcare, roads and other comprehensive plans. It will equally help government decide whether new schools, healthcare centers and other public services are needed to meet the needs of persons with disabilities. Governmental plans without figures and data of its citizens will result to marginalization and political or economic deprivation of certain set of people such as those with disabilities within the society (UN Development Group 2015). 
As noted before, SDGs international and regional instruments on disability stress the importance of having sound disability statistics and valid disability database. At the national level, the Ministry of Gender, Labour and Social Development, (2016) acknowledges the need for maintaining a comprehensive data on persons with disabilities in the country. There are many reasons why the above stated instruments and documents acknowledged the need and importance of disability statistics or valid disability database. Just as any quality statistical information or data, quality disability information is needed for service programming and development, capacity building, budgeting, and seeking international assistance, among many others. Specifically, appropriate disability statistics or data is important for the following three reasons: monitoring the level of functioning in a population; for provision of services and equalization of opportunity.

In congruence, Yula \& Kesi (2014) and Oroni (2015) revealed that the International Disability Alliance and the International Disability and Development Consortium call on Member States to declare as a principle the disaggregation of all relevant targets by disability and in addition to include specific disability indicators matching all targets referencing persons with disabilities into the indicator framework. Consequently, this will ensure that indicators in the SDG framework will reflect the scope and ambition of the SDG goals and targets, while realizing the principle of no-one left behind. Failure to specify the full list of categories for disaggregation - including the one on disability status - is out of step with the 2030 Agenda that specifies that data should be disaggregated by income, gender, age, race, ethnicity, migratory status, disability, geographic location and other characteristics relevant in national context. Overlooking these categories, again, undermines the concept of leave no one behind reflected in the 2030 Agenda. Disaggregation is important for the inclusion of excluded populations. For example, an indicator that analyses the entire population cannot monitor the progress of subpopulations. Consequently, subpopulations, such as persons with disabilities, will be excluded from monitoring purposes and targets will not be realized for them.

\section{RECOMMENDATIONS}

Based on the findings of the study, the following recommendations are made:

- The Federal Government should by law establish National Commission on Sustainable Development for Persons with Disabilities to take charge of all disability matters across all the 17 goals of post 2015 development agenda so as facilitate their implementation.

- The government should establish workable follow up mechanisms at federal, state and local government levels so as to monitor evaluate and hold key national SDGs actors accountable for implementation of the development agenda.

- National Bureau of Statistics should be empowered by the federal government to conduct and disaggregate baseline data by disabilities to promote effective planning, budgeting and implementation of sustainable inclusive education for the benefit of all.

\section{CONCLUSION}

The 2012 Rio+20 conference initiated an intergovernmental process to identify a set of universal, integrated and transformational Sustainable Development Goals (SDGs). Negotiations over the SDGs are scheduled to deliver an actionable post-2015 development agenda by the end of 2015. To reach this deadline, the SDGs will draw some inspiration from the Millennium Development Goals (MDGs). But while MDGs have been widely credited for advancing international development for the past decade and a half, they included hastily-designed strategies that did not significantly lead their implementation. Thus, national recommitment to the global vision in achieving sustainable inclusive education is required through revolution of the whole weak and ineffective logistical strategies to viable ones such as establishment of National Commission on Sustainable Development for Persons with Disabilities, establishment of workable follow up mechanism and disaggregation of baseline data by disability.

\section{REFERENCE LIST}

Abimbola, J.U. and Egeno, G.K. (2013). The disabled: The Millennium Development Goals: Overlooked Priority Group. Journal of Immigrant and Disability Studies 10: 426-30.

Akuaya, A.A. (2007). Computable general equilibrium models for sustainability impact assessment: Status quo and prospects. Ecological Economics, 60: 49-64.

Buskara, G.F. and Tope, N. (2009). The role and place of the high-level political forum in strengthening the global institutional framework for sustainable development. Journal of Sustainable Development, 233-256

Diabi, E.E. and Luku, F.I. (2012). Achieving Sustainable Development Goals (SDGs) through transformative governance practices and vertical collaboration at the national and sub-national levels in Africa. Abuja: 
NERDC

Dullar, F.T. and Ekeye, W.R. (2014). Reviewing the Post-2015 Sustainable Development Goals and Partnerships: A Proposal for a Multi-level Review at the High-level Political Forum. Berlin: StiftungWissenschaft und Politik, German Institute for International and Security Affairs.

Eriet, S.R. and Kufre, V.I. (2012). Measuring Welfare for Small but Vulnerable Groups: Post 2015 Agenda and Disability in Nigeria. Journal of African Economies, 10(4): 603-631.

Forlin, D. and Yaya, D.C. (2014). Measuring Education for the sustainable Development Goals: Reflections on Targets, Indicators and a Post-2015 Framework. Journal of Human Development and Capabilities 15: 17687

Gounla, J. and Esheh, C.C. (2015). New ways of looking at old issues: Strategies for SDGs. Journal of Development Economics 57: 259-287.

Hugh, S.D. and Jage, W. (2013). Winning strategies for a sustainable future. Melbourne: Ringlet Press

Mener, A.M. and Held, D.B. (2007). Monitoring the implementation of SDGs for the minority population in Nigeria: The gap in the MDGs.Izzi: Dulex Press

Ministry of Gender, Labour and Social Development, (2016). Disability, Poverty and the New Development Agenda. Retrieved from www.disability.se.klar.net/docs/agenda.doc.on 20 October, 2016.

Olise, D.V. and Rawat, G.B. (2013). Conceptualizing sustainable development: An assessment methodology connecting values, knowledge, worldviews and scenarios. Ecological Economics, 68: 1006-1019.

Oluwole, M. and Akinbile, J.I. (2015). Education and national development in Nigeria. International Journal on Education, 5: 34-4

Opara, M. and Akanbi, V. (2005). Access to Mainstream Micro-Finance Institutions: Lessons from Uganda. Paper presented at the Joint UNECA/Leonard Cheshire Disability Conference "UN Convention on the Rights of Persons with Disabilities: A Call for Action on Poverty, Lack of Access and Discrimination", Addis Ababa, May 2008.

Oroni, H.O. (2015). Strengthening National Statistical Systems to Monitor Global Goals: Post-2015 Reflections. Retrieved from (http://www.oecd.org/dac/POST-2015\%20P21.pdf. On 6 September, 2016.

Ughali, H. and Hualo, C.S. (2014). The universal periodic review of the UN Human Rights Council: An assessment of the first session. Chinese Journal of International Law, 4 (2) $711-729$

UN Development Group (2015). Developing the Post-2015 Development Agenda: Opportunities at the National and Local Levels. Retrieved fromhttp://www.undp.org/content/dam/undp/library/ MDG/Post2015SDG/UNDP-MDG-Delivering-Post-2015-Report-2014.pdf on 19 September 2016.

UN General Assembly (2015). Transforming our World: The 2030 Agenda for Sustainable Development. Retrieved from: http://www.un.org/ga/search/view_doc.asp?symbol=A/RES/70/1\&Lang=E on 19 September, 2016.

UNDG (2015). Participatory Monitoring for Accountability: Critical Enablers for the Successful Implementation of the Sustainable Development Goals, Draft Report. New York: UNDG.

Upah, S.U. and Egbe, H.I. (2012). Mainstreaming Disability in International Development. Disability and Society 27: 1-14.

Wale, H. and Futar, D.V. (2015). Disability and Inclusive Development. London: Leonard Cheshire Disability.

Yula, A.D. and Kesi, I.I. (20014). National indicators and a monitoring framework for Sustainable Development Goals: Launching a data revolution for the SDGs. Journal of Development, 14(2) 78-90 